\title{
Immunogenicity of decellularized cryopreserved allografts in pediatric cardiac surgery: Comparison with standard cryopreserved allografts
}

John A. Hawkins, $\mathrm{MD}^{\mathrm{a}}$

Neal D. Hillman, $M^{a}$

Linda M. Lambert, $\mathrm{MD}^{\mathrm{a}}$

Jamison Jones, $M D^{\mathrm{a}}$

Gregory B. Di Russo, MDa

Tracie Profaizer, $\mathrm{BS}^{\mathrm{C}}$

Thomas C. Fuller, $\mathrm{PhD}^{\mathrm{c}}$

L. LuAnn Minich, MD ${ }^{\mathrm{b}}$

Richard V. Williams, MD ${ }^{\mathrm{b}}$

Robert E. Shaddy, MD
From the Departments of Pediatric Cardiothoracic Surgery ${ }^{\mathrm{a}}$ and Pediatric Cardiology, ${ }^{\text {b }}$ Primary Children's Medical Center and University of Utah and the Histocompatibility and Immunogenetics Laboratory, ${ }^{\mathrm{c}}$ University of Utah Hospital, Salt Lake City, Utah.

Read at the Eighty-second Annual Meeting of The American Association for Thoracic Surgery, Washington, DC, May 5-8, 2002.

Received for publication June 7, 2003; revisions requested Aug 1, 2002; revisions received Sept 16, 2002; accepted for publication Oct 10, 2002

Address for reprints: John A. Hawkins, MD, Pediatric Cardiothoracic Surgery, Primary Children's Medical Center, $100 \mathrm{~N}$ Medical Dr, Salt Lake City, UT 84113 (Email: jhawkins@med.utah.edu).

J Thorac Cardiovasc Surg 2003;126:247-53

Copyright $\odot 2003$ by The American Association for Thoracic Surgery

$0022-5223 / 2003 \$ 30.00+0$

doi:10.1016/S0022-5223(03)00116-8
Background: Recognition of the immunogenicity of standard cryopreserved allografts has led to the development of new decellularized allografts (CryoValve SG; CryoLife, Inc, Kennesaw, Ga). This preliminary study examined the HLA antibody response to these decellularized allografts and compared it with the response to standard allograft material.

Methods: We prospectively measured the frequency of panel-reactive HLA class I (HLA-A, HLA-B, and HLA-C) and class II (HLA-DR/DQ) alloantibodies in 14 children (age $8.5 \pm 7.9$ years) receiving decellularized, cryopreserved allografts, including 6 undergoing allograft patch insertion and 8 with a valved pulmonary allograft. We compared them with 20 historical control subjects (age $1.7 \pm 2.4$ years) undergoing implantation of standard cryopreserved allografts, 8 with valves and 12 with allograft patch. All patients had panel-reactive antibody levels measured before and at 1, 3, and 12 months after the operation. HLA class I and class II panel-reactive antibody levels were determined with a sensitive flow cytometry technique.

Results: We found panel-reactive antibody levels in decellularized allografts to be elevated slightly from preoperative levels for both class I and class II antibodies at 1,3 , and 12 months $(P>.05)$. The panel-reactive antibody level for both class I and class II antibodies were significantly lower for decellularized allografts as compared to standard allografts. Functionally, the allografts were similar with decellularized valved grafts showing a peak echo-determined systolic gradient of $13 \pm 15 \mathrm{~mm} \mathrm{Hg}$ at $8 \pm 2.6$ months postoperatively as compared to a gradient of $24 \pm 18 \mathrm{~mm} \mathrm{Hg}$ measured $12 \pm 6$ months postoperatively in standard allografts $(P=.11)$.

Conclusions: Decellularized grafts elicited significantly lower levels of class I and class II HLA antibody formation at 1, 3, and 12 months after implantation than did standard cryopreserved allografts. Early hemodynamic function of decellularized grafts was similar to that of standard cryopreserved allograft valves. Further experience is necessary to determine whether the reduced immunogenicity of decellularized allografts will truly allow tissue ingrowth and improved long-term durability in patients. 


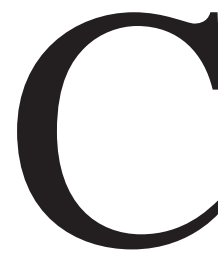

ryopreserved human allograft material is extensively used in cardiac surgery to reconstruct a variety of congenital cardiac defects and abnormalities. Because of the widespread use of this cryopreserved allograft material, immunologic consequences of allograft implantation have been investigated, as illustrated by reports from several groups of the activation of anti-HLA antibodies. ${ }^{1-3}$ A new decellularized cryopreserved allograft preparation has become available that theoretically will eliminate the immune response and, it is hoped, allow host cell ingrowth and better durability. ${ }^{4}$ Only limited experience and information with this new tissue has been available to date, and only with older patients. ${ }^{5,6}$ Before the use of this human cryopreserved decellularized tissue can become widespread, the immunologic consequences and implications of this new tissue and valve preparation must be evaluated in children. Infants and children tend to have the greatest immunologic reaction to cryopreserved allograft material, ${ }^{7}$ with a shorter period of freedom from reintervention after valved allograft implantation than is seen in adult patients. ${ }^{8,9}$ Thus infants and children may have the most to gain from the development of newer technologies that abolish immunogenicity and prolong durability.

This preliminary study was undertaken to examine the immunogenicity of these new cryopreserved allograft valves and nonvalved patch tissue grafts as related to the development of anti-HLA antibodies. In addition, we compared this new tissue with more traditional cryopreserved allografts in terms of both functional results and rate of calcification.

\section{Patients and Methods}

\section{Patients}

We prospectively enrolled 14 patients who received decellularized cryopreserved allograft material (CryoValve SG; CryoLife, Inc, Kennesaw, Ga) for reconstruction of congenital cardiac defects. Ages of the patients ranged from 22 days to 21 years (mean \pm SD $8.5 \pm 7.9$ years). Diagnoses included truncus arteriosus in 2 patients, tetralogy of Fallot in 3 patients, aortic stenosis with pulmonary valve replacement for concomitant Ross procedure in 3 patients, pulmonary stenosis and insufficiency in 1 patient, supravalvular pulmonary stenosis in 2 patients, supravalvular aortic stenosis in 1 patient, pulmonary artery aneurysm with pulmonary valve insufficiency in 1 patient, and pulmonary atresia with intact ventricular septum in 1 patient. The procedures included insertion of a valved pulmonary allograft in 8 cases, pulmonary artery monocusp insertion in the right ventricular outflow tract in 2 cases, supravalvular pulmonary patch angioplasty in 3 cases, and allograft patch aortoplasty in 1 case. The types of allografts inserted included valved pulmonic allografts in 8 cases, pulmonary artery patch (nonvalved) allografts in 4 cases, and pulmonary artery monocusp patch allografts in 2 cases. Seven of the 14 patients had undergone previous cardiac surgery, all without allograft implantation.

Historical control subjects were used for comparison and consisted of 20 patients unselected from previous studies who had undergone implantation of standard cryopreserved allograft material with identical techniques and methods of HLA testing, including both class I and class II antibodies. ${ }^{10,11}$ This standard group underwent implantation of 8 valved allografts, 7 allograft patches, and 5 monocusp pulmonary patches. Ages of patients ranged from 12 days to 7 years (mean \pm SD $1.7 \pm 2.2$ years). Implantation techniques, study methods, and testing were identical for both decellularized and standard allograft groups, and no attempt was made to match $\mathrm{ABO}$ blood types in either group.

\section{Allografts}

All allografts in this study were obtained from CryoLife, Inc. Standard cryopreserved allograft material was considered to be allograft material that was harvested and cryopreserved according to previously published methods. ${ }^{12,13}$ Decellularized cryopreserved allograft material (SynerGraft; CryoLife, Inc) is prepared by harvesting techniques similar to those used for standard allograft material but undergoes a decellularization process that first involves cell lysis in hypotonic sterile water solution. After that, the allograft tissue is equilibrated in buffer and is treated by enzymatic digestion of nucleic acids with a combined solution of ribonuclease and deoxyribonuclease. The allograft tissue then undergoes a multiday washout in isotonic neutral buffer to further reduce cellular staining when evaluated with hematoxylin and eosin staining of cryosectioned tissue. ${ }^{4}$ The processed decellularized valves are then cryopreserved according to a controlled rate freezing protocol. ${ }^{14}$ The resulting decellularized cryopreserved allografts have been shown to have approximately a $99 \%$ reduction in staining of endothelial and interstitial cellular elements, as well as marked reduction in staining for class I and class II histocompatibility antigens. ${ }^{5}$

\section{Study Methods}

The study protocol was approved by the institutional review board at Primary Children's Medical Center as well as the University of Utah Medical Center. Informed consent was obtained from the parents or guardian of each patient before entrance into the study. Blood was obtained for HLA panel-reactive antibody (PRA) screens and specificity determination at the following times: immediately before the operation and approximately 1,3 , and 12 months after implantation of the allograft material. As part of the protocol, all patients received only blood products that had undergone both irradiation and leukocyte filtering to remove allogeneic white blood cells that could sensitize the patients. ${ }^{15}$ All blood products were irradiated with cesium 137 at $30 \mathrm{~Gy}$ and were filtered with the use of Purecell leukocyte reduction filters (Pall Biomedical Products Co, East Hills, NY). Children with identified immunologic deficiencies such as DiGeorge syndrome were excluded from the study.

HLA-A, HLA-B, and HLA-C (class I) and HLA-DR/DQ (class II) antibodies were determined by a sensitive flow cytometry procedure. ${ }^{16}$ This technique uses affinity-purified, soluble class I and class II antigens from 30 different cell lines that are coupled individually to latex beads and then pooled together to create a 
TABLE 1. Class I and class II alloantibody measurements in 14 patients after implantation of decellularized cryopreserved allografts and 20 patients after implantation of standard cyropreserved allografts

\begin{tabular}{|c|c|c|c|c|}
\hline \multirow{3}{*}{$\begin{array}{l}\text { Time since allograft } \\
\text { implantation }\end{array}$} & \multicolumn{4}{|c|}{ PRA (\%, \pm SD) } \\
\hline & \multicolumn{2}{|c|}{ Decellularized allografts $(n=14)$} & \multicolumn{2}{|c|}{ Standard allografts $(n=20)$} \\
\hline & Class I & Class II & Class I & Class II \\
\hline Before operation & $0.3 \% \pm 1 \%$ & $0 \% \pm 0 \%$ & $5 \% \pm 11 \%$ & $0.3 \% \pm 1 \%$ \\
\hline $33 \pm 14 d$ & $5 \% \pm 14 \% *$ & $7 \% \pm 15 \% *$ & $57 \% \pm 38 \%$ & $35 \% \pm 36 \%$ \\
\hline $3.3 \pm 0.7 \mathrm{mo}$ & $12 \% \pm 30 \% *$ & $14 \% \pm 19 \% *$ & $81 \% \pm 9 \%$ & $59 \% \pm 33 \%$ \\
\hline $12 \pm 4 \mathrm{mo}$ & $8 \% \pm 16 \% *$ & $6 \% \pm 10 \% *$ & $73 \% \pm 38 \%$ & $38 \% \pm 24 \%$ \\
\hline
\end{tabular}

${ }^{*} P<.05$ versus standard allograft.

panel that represents the majority of serologically recognized HLA class I and class II alloantigens (Flow-PRA I and II Beads; One Lambda, Canoga Park, Calif). The beads were incubated with 0.02 $\mathrm{mL}$ of patient serum and then washed washing and stained with saturating fluorescein-conjugated goat antihuman immunoglobulin G. After analysis on a Becton Dickinson FACScan flow cytometer (BD Immunocytometry Systems, San Jose, Calif), the percentage of fluorescent positive beads, indicative of the percentage of PRA, was calculated.

Patients with valved allografts in both groups underwent echocardiographic follow-up consisting of standard surface 2-dimensional and Doppler echocardiography. Allograft stenosis was evaluated with standard Doppler techniques. The peak velocity across the valved conduits was obtained with pulsed or continuous-wave Doppler evaluation, and the gradient was determined with the modified Bernoulli equation. Pulmonary valve regurgitation was graded echocardiographically according to a method described previously by us that has been validated and compared with traditionally used angiographic measures. ${ }^{17}$ According to this method, the ratio of the width of the pulmonary regurgitation color jet to the diameter of the valve annulus in early diastole is used as semiquantitative index of severity. A color jet to annulus ratio less than 0.4 is classified as mild $(1+)$, a ratio of at least 0.4 but less than 0.7 is classified as moderate $(2+)$, and a ratio of at least 0.7 is classified as severe $(3+)$.

\section{Statistical Analysis}

Comparisons between continuous data were made with unpaired $t$ test or analysis of variance and Scheffé post hoc analysis. All data were expressed as mean $\pm \mathrm{SD}$.

\section{Results}

Results are shown in Table 1. Both class I and class II HLA antibodies were elevated slightly from baseline values in patients receiving decellularized grafts at 1,3 , and 12 months, although these differences were not significant. However, all values beyond baseline preoperative time point for both class I and class II HLA antibodies were significantly less in decellularized allografts than their corresponding values at the same time period for standard allografts. Overall, 9 of the 14 patients exhibited no humoral response, as defined as an elevation of PRA greater than
$10 \%$ for either class I or class II antibodies at any time period after the operation. Two other patients exhibited elevation of PRA greater than $10 \%$ for both class I and class II antibodies at 1 month, with 1 patient showing resolution of the PRA to less than $10 \%$ for class II antibodies by 1 year after the operation. Three additional patients showed elevation of PRA greater than $10 \%$ for just class II antibodies by 3 months after the operation, but by 1 year only 2 of these patients still had a PRA level greater than $10 \%$ for class II antibodies. Results for both class I and class II HLA antibodies in the standard allograft group are shown in Table 1 and have been previously reported. ${ }^{10,11}$

Echocardiographic evaluation occurred at $8 \pm 2$ months after implantation in the 8 patients receiving decellularized valved allografts and showed an average peak gradient of 13 $\pm 15 \mathrm{~mm} \mathrm{Hg}$, compared with an average peak gradient of $24 \pm 18 \mathrm{~mm} \mathrm{Hg}$ measured $12 \pm 6$ months after the operation in the 8 patients receiving standard cryopreserved valved allografts $(P=.11)$. Evaluation for pulmonary valve insufficiency in the patients receiving decellularized valved allografts showed 5 patients with trivial or no pulmonary valve regurgitation and 3 with moderate pulmonary valve regurgitation. The standard cryopreserved valved allografts demonstrated trivial or no pulmonary valve regurgitation in 3 patients, mild regurgitation in 3 , moderate regurgitation in 1 , and severe regurgitation in 1 . One decellularized valved allograft was explanted at 4 months concomitantly with resection of an aneurysm of an untreated autologous pericardial outflow patch used to "hood" the valved allograft. Pathologic examination of this explant revealed cellular ingrowth into the media of the graft (Figure 1), but the type of cell could not be identified. Special stains were also done to identify endothelial cells, but there was no definitive evidence of endothelial cells on the luminal surface of the explanted graft at 4 months. One patient $(n=1 / 14,7.1 \%)$ exhibited calcification of a decellularized monocusp patch within 1 year after the operation, as opposed to 1 patient (n $=1 / 20,5 \%$ ) with calcification of a standard valved allograft within 1 year after the operation. 


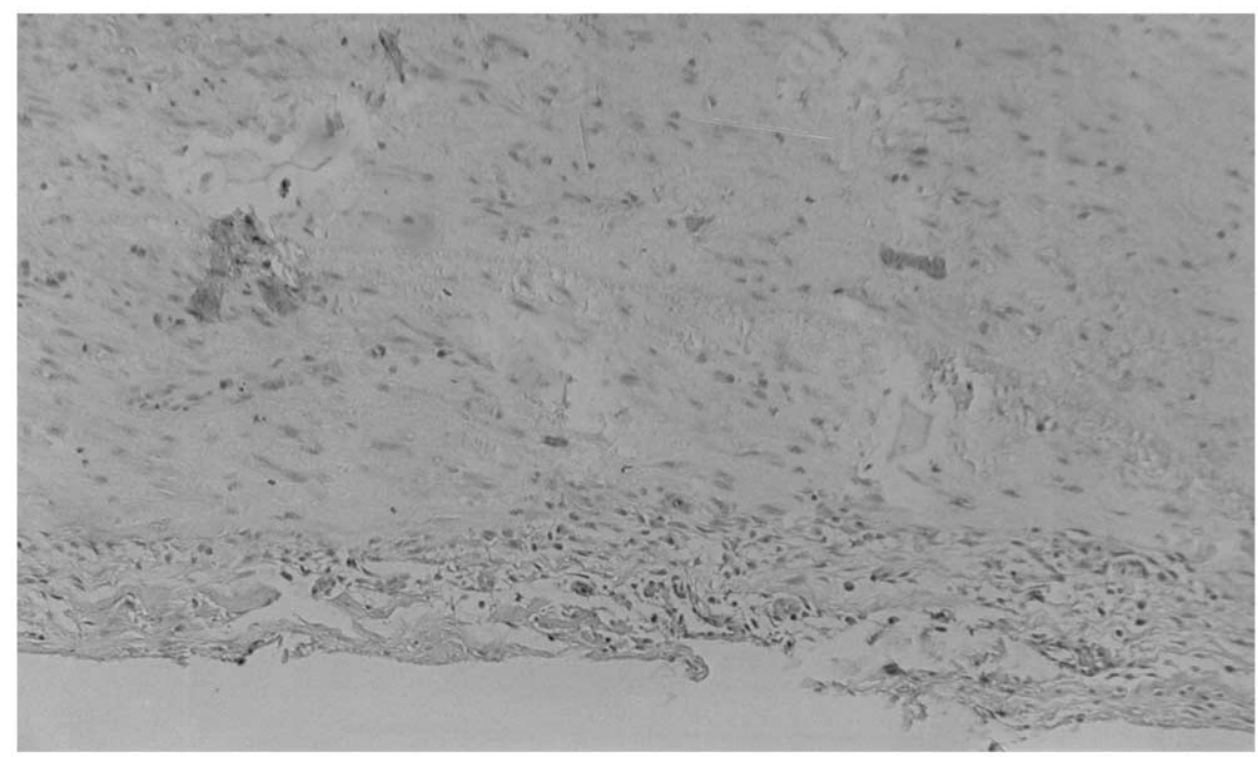

Figure 1. Photomicrograph of decellularized cryopreserved pulmonary allograft explanted 4 months after operation. There is evidence of cellular ingrowth into media of graft, but no apparent cell staining of endothelial cells on luminal side of graft (bottom).

\section{Discussion}

Cryopreserved allograft material is widely used in the definitive repair and palliation of a variety of congenital cardiac defects and has included valved allografts, monocusp pulmonary valve patches, and nonvalved allograft patch material. Standard cryopreserved allograft material demonstrates preservation of endothelial and valve architecture and viability. ${ }^{18}$ This viability may not be a positive attribute, as initially thought, if it contributes to immunogenicity and elicits a more vigorous immunologic reaction from the recipient, especially if the heightened immune response contributes to accelerated degeneration of allograft valves. Previous studies in human subjects have demonstrated formation of both class I and class II anti-HLA antibodies in patients after allograft implantation with homovital antibiotic-preserved allografts, as well as in patients receiving standard commercially available cryopreserved valved allografts. ${ }^{2,3,19-22}$ An immunologically neutral graft has therefore been considered desirable, leading to the development of a new cryopreserved allograft preparation (CryoValve) that has been decellularized to avoid introduction of immunogenic cells into the recipient. This process is claimed to leave the valve biologic matrix and structure intact. ${ }^{4}$ When implanted in an animal model, the decellularized valves are repopulated with fibroblasts and endothelial cells of the recipient; the result more closely approximates a normal valve as well as being immunologically neutral. ${ }^{4}$ Although our single explanted valve demonstrated cellular ingrowth into the media of the graft, we were unable to demonstrate definitive endothelial cell ingrowth (Figure
1) such as has been reported for animal studies. ${ }^{4}$ There has been only one previous group reporting the use of these decellularized allografts in human subjects, and their experience involved primarily adult patients. ${ }^{5,6}$ Similar to our current study, they demonstrated that more than $90 \%$ of patients without preoperative HLA antibodies continued to have class I antibody levels less than $10 \%$ at 1 and 3 months after the operation. ${ }^{6}$

This study demonstrated in a prospective manner that these new decellularized allografts elicit a significantly reduced immune response to both class I (anti-HLA-A, antiHLA-B, and anti-HLA-C) and class II (anti-HLA-HLA DR/DQ) alloantigens. Why a few patients respond immunologically (PRA $\geq 10 \%$ ), even in a transient fashion, while most do not, cannot be yet be determined. The alloantibody elicited in these grafts toward HLA-DR antigens is intriguing and may suggest some residual cells, notably highly immunogenic, HLA class II-expressing dendritic cells that may be more resistant to the decellularization process.

Although it has not been definitely proved, we and others have speculated that the vigorous immune response measured by an elevated PRA may have significant negative effects on allograft function and longevity. ${ }^{2,3,7,10,11}$ The advantages of reduced immunogenicity are thus 2-fold. First, an absent or at least reduced immunologic response will allow investigators to better sort out the role that immunology plays in allograft failure in children. Although immunologic factors are likely to play a role in allograft failure, they are intertwined with other factors associated with graft failure, such as patient age, graft size, donor age, 
and allograft type, making isolation of a single factor difficult. Second, the presence of both class I and class II HLA antibodies has significant implications if future heart or other organ transplantation is needed. Some children receiving allograft valves or allograft patch material have significant heart disease or undergo palliative procedures anticipated to result in late transplantation. Examples of a group of patients who are at risk for needing late transplantation include those with single-ventricle physiology undergoing palliative procedures with pulmonary artery reconstruction with allograft patches and children with hypoplastic left heart syndrome undergoing stage I palliation with a Norwood procedure. The presence of donor-specific HLA class I and class II antibodies has been shown to increase the risk of acute or hyperacute cardiac allograft rejection and to decrease graft survival. ${ }^{23,24}$ In addition, extremely high and sustained PRA levels, as we $\mathrm{e}^{3,10,11}$ and others ${ }^{19-22}$ have previously reported, may preclude or at least significantly delay transplantation until a crossmatch-compatible donor can be identified. Implantation of decellularized grafts, with the lower level of PRA and even the absence of a response in most cases, removes this impediment to transplantation.

There are several limitations of this study that make it harder to determine whether decellularized allografts are really an advance with respect to standard cryopreserved allografts. First, this study is limited by a duration of follow-up of less than 1 year and the relatively small number of patients followed up during that time. Deterioration of cryopreserved valved allografts is usually seen in the 3- to 5-year range for infants and the 5- to 10-year range for older children. ${ }^{8,9}$ It will therefore take much larger numbers and longer follow-up to document definitive improvement in graft durability and function. Second, the comparison group in this study was a historical group rather than a randomized cohort. Although the methods used in the two study groups were identical, the ages of the two groups were different. There has been previous evidence of an increased immunologic response in infants relative to adults, but we have not seen any difference in PRA response in either class I or class II antibodies in infants as compared with older children in any of our previous studies. ${ }^{3,10,11,25,26}$ Use of a randomized group of larger numbers of patients would allow the most accurate comparison. In multiple other studies with standard cryopreserved allografts, however, we have never been able to demonstrate the low HLA antibody levels seen with the decellularized allografts in this study. $3,10,11,25,26$ Third, histologic confirmation of tissue ingrowth and the long-term biomechanical properties beyond animal studies are not known. ${ }^{4}$ The decellularized allograft may possess unique biomechanical properties that result in unknown extra risk of complications, such as aneurysm or pseudoaneurysm formation, cusp dehiscence, and possible other long-term effects of any differences in compliance. Only a prospective, randomized trial with longer follow-up will most accurately answer these questions. It may be even more difficult to establish superiority or inferiority of nonvalved allograft patches, because there is a low incidence of stenosis with standard nonvalved allograft material. At present, benefits of decellularized nonvalved allograft patches can only been measured clinically by the development of HLA antibodies and the possible detrimental effect that this may have on a patient with regard to allograft function and possible future transplantation. Longer-term experience with these decellularized valves is necessary to balance the cost-benefit relative to standard cryopreserved allografts and determine whether the additional cost and potentially unknown long-term complications are outweighed by the advantages of low immunogenicity and possible improvements in durability.

\section{References}

1. Cochran RP, Kunzelman KS. Cryopreservation does not alter antigenic expression of aortic allografts. J Surg Res. 1989;46:597-9.

2. Smith JD, Ogino H, Hunt D, Laylor RM, Rose ML, Yacoub MH. Humoral immune response to human aortic valve homografts. Ann Thorac Surg. 1995;60(2 Suppl):S127-30.

3. Shaddy RE, Hunter DD, Osborne KA, Lambert LM, Minich LL, Hawkins JA, et al. Prospective analysis of HLA immunogenicity of cryopreserved valved allografts used in pediatric heart surgery. Circulation. 1996;94:1063-7.

4. O'Brien MF, Goldstein S, Walsh S, Black KS, Elkins R, Clarke D. The SynerGraft valve: a new acellular (nonglutaraldehyde-fixed) tissue heart valve for autologous recellularization first experimental studies before clinical implantation. Semin Thorac Cardiovasc Surg. 1999;11: 194-200.

5. Elkins RC, Dawson PE, Goldstein S, Walsh SP, Black KS. Decellularized human valve allografts. Ann Thorac Surg. 2001;71(5 Suppl): S428-32.

6. Elkins RC, Lane MM, Capps SB, McCue C, Dawson PE. Humoral immune response to allograft valve tissue pretreated with an antigen reduction process. Semin Thorac Cardiovasc Surg. 2001;4:82-6.

7. Rajani B, Mee RB, Ratliff NB. Evidence for rejection of homograft cardiac valves in infants. $J$ Thorac Cardiovasc Surg. 1998;115:111-7.

8. Hawkins JA, Bailey WW, Dillon T, Schwartz DC. Midterm results with cryopreserved allograft valved conduits from the right ventricle to pulmonary arteries. J Thorac Cardiovasc Surg. 1992;104:910-6.

9. Clarke DR, Campbell DN, Hayward AR, Bishop DA. Degeneration of aortic valve allografts in young recipients. J Thorac Cardiovasc Surg. 1993; 105:934-42.

10. Hawkins JA, Breinholt JP, Fuller TC, Lambert LM, McGough EC, Shaddy RE. Class I and class II anti-HLA antibodies after implantation of cryopreserved allograft material in pediatric patients. $J$ Thorac Cardiovasc Surg. 2000;119:324-30.

11. Breinholt JP, Hawkins JA, Lambert LM, Fuller TC, Profaizer T, Shaddy RE. A prospective analysis of the immunogenicity of cryopreserved nonvalved allografts used in pediatric heart surgery. Circulation. 2000;102(Suppl 3):III179-82.

12. McNally RT, Heacox AE, Brockbank KG. Short-term follow-up of cryopreserved allograft valves and valved conduits from the CryoLife clinical registry. In: Yankah AC, Hetzer R, Miller DC, et al, editors. Cardiac valve allografts 1962-1987. Darmstadt, Germany: Steinkopff Verlag; 1988. p. 323-32.

13. Heacox AE, McNally RT, Brockbank KG. Factors affecting the viability of cryopreserved allograft heart valves. In: Yankah AC, Hetzer R, Miller DC, et al, editors. Cardiac valve allografts 1962-1987. Darmstadt, Germany: Steinkopff Verlag; 1988. p. 37-42.

14. McNally RT, Heacox A, Brockbank KG, Bank HL, inventors. Method 
for Cryopreserving Heart Valves. Cryolife, Inc., Assignee. Jan 2, 1987, US patent 4,890,457.

15. The Trial to Reduce Alloimmunization to Platelets Study Group. Leukocyte reduction and ultraviolet B irradiation of platelets to prevent alloimmunization and refractoriness to platelet transfusions. N Engl J Med. 1997;337:1861-9.

16. Pei R, Wang G, Tarsitani C, Rojo S, Chen T, Takemura S, et al. Simultaneous HLA class I and class II antibodies screening with flow cytometry. Hum Immunol. 1998;59:313-22.

17. Williams RV, Minich LL, Shaddy RE, Pagotto LT, Tani LY. Comparison of Doppler echocardiography to angiography for determining the severity of pulmonary regurgitation. Am J Cardiol. 2002;89:143841.

18. O’Brien M, Stafford E, Gardner M, Pohlner P, McGiffin D. A comparison of aortic valve replacement with viable cryopreserved and fresh allograft valves with a note on chromosomal studies. $J$ Thorac Cardiovasc Surg. 1987;94:812-23.

19. Smith JD, Hornick PI, Rasmi N, Rose ML, Yacoub MH. Effect of HLA mismatching and antibody status on "homovital" aortic valve homograft performance. Ann Thorac Surg. 1998;66(6 Suppl):S212-5.

20. Hoekstra F, Knoop C, Vaessen L, Wassenaar C, Jutte N, Bos E, et al. Donor-specific cellular immune response against human cardiac valve allografts. J Thorac Cardiovasc Surg. 1996;112:281-6.

21. Hoekstra F, Witvliet M, Knoop C, Akkersdijk G, Jutte N, Bogers A, et al. Donor-specific anti-human leukocyte antigen class I antibodies after implantation of cardiac valve allografts. J Heart Lung Transplant. 1997;16:570-2.

22. Hoekstra FM, Witvliet M, Knoop CY, Wassenaar C, Bogers AJ, Weimar W, et al. Immunogenic human leukocyte antigen class II antigens on human cardiac valves induce specific alloantibodies. Ann Thorac Surg. 1998;66:2022-6.

23. Smith JD, Danskine AJ, Rose ML, Yacoub MH. Specificity of lymphocytotoxic antibodies formed after cardiac transplantation and correlation with rejection episodes. Transplantation. 1992;53:1358-62.

24. Suciu-Foca N, Reed E, Marboe C, Harris P, Yu PX, Sun YK, et al. The role of anti-HLA antibodies after heart transplantation. Transplantation. 1991;51:716-24.

25. Shaddy RE, Hunter DD, Osborn KA, Hawkins JA, Fuller TC. Persistence of anti-HLA antibodies beyond one year in children receiving cryopreserved valved allografts at surgery. Am J Cardiol. 1997;80: 358-9.

26. Shaddy RE, Lambert LM, Fuller TC, Profaizer T, Thompson DD, Baker SI, et al. A prospective randomized trial of azathioprine in children receiving cryopreserved valved allografts for repair of congenital heart defects. Ann Thorac Surg. 2001;71:43-7.

\section{Discussion}

Dr John E. Mayer, Jr (Boston, Mass). First let me congratulate Hawkins and colleagues on a clear presentation of important work. The finding that decellularized homografts do not elicit the same antibody response as cellular grafts is of significant interest, particularly for patients who ultimately may require transplantation. I have found it interesting from a historical and scientific standpoint how our pendulum has swung from the concept years ago, when we were told that preserving the viability of cells on homografts was critical to their long-term function, to the other end of the spectrum. Now we're being told that decellularization will actually be a better process.

I have no specific comments about the antigenicity. And in some ways I think that the findings are almost what one would predict. But if one disregards those immunologic considerations, I wondered about a few things.

First, Dr Hawkins, you have shown that the explanted graft of homograft material was cellularized, but we don't really know what kind of cells they are. In particular, I wondered whether you had any notions about what the cells on the luminal surface were like. Have you done any studies on whether they're true endothelial cells? One of the fundamental differences between human beings and most experimental animals is that the ability to reendothelialize seems to be much less, growing in a few millimeters from either end of the anastomosis between the artificial material and the true native vessel. I wondered if you had any information about that.

Second, on the basis of your clinical experience with this material, could you comment on the effects of the decellularization process on the structural and hemodynamic performance of the implanted material?

Dr Hawkins. Actually, we did do some special stains in this case. I hesitate to make too many conclusions on the basis of a single patient, but that happens to be all that I have. We did do stains for endothelial cells and could not find any when we looked at multiple areas with multiple stains. There is no doubt that there are cells present. I could conjecture that they're probably fibroblasts. But are they fibroblasts that function? Not only do we need, at least theoretically, a graft that has normal cells that have grown into it, we need those normal cells to function to the point that they participate in protein and collagen turnover. So we don't really know the answer to the question of whether these cells are functional. My guess is that they're probably fibroblasts, and at least in this case they were not endothelialized at 4 months.

Your second question has to do with my clinical experience with the hemodynamic function of these decellularized grafts. I think that a conclusion from the data that I presented today would be premature. There is no way to know at this point what the hemodynamic data are of these valved allografts versus standard. They appear to be equivalent. But are they biomechanically identical to the human valve? I don't know. I think that's the claim, but I don't think we really know yet. My own personal opinion is that the tissue seems - and I stress that this is an anecdotal observation-to stretch more and to be a bit more elastic than standard allograft material; however, I believe that the experimental data from the company and animal data indicate that it's biomechanically the same.

Dr W. Steves Ring (Dallas, Tex). Do you have any data on what might be an appropriate third control group? That would be patients who undergo bypass surgery. Even though you've filtered your blood, what's the elevation in the flow PRA in that particular group of patients where you don't have a homograft?

Dr Hawkins. When we did our original studies back in 1996, we did a control group of about 14 or 15 children who underwent a variety of cardiac procedures that did not include implantation of a homograft but did include bypass with Leukopore-filtered irradiated blood. Their PRA at 1 month and 3 months was 0 . We did not do the 12-month time point, because we considered that it was probably not ethical to put them through yet another blood sampling for to check a level that was 0 at 3 months. So we have done such a control group. I did not include it in this report for the sake of time.

Dr Marshall L. Jacobs (Philadelphia, Pa). Earlier today Dr Zahid Amin, in discussing acute homograft conduit failure, identified persistent postoperative fever as a marker or predictive factor with an odds ratio of 9.1, or something that seemed rather compelling. It's a simple observation to make. Was there any difference in the incidence of persistent postoperative fevers in your decellularized patient group as compared with your historical control group? 